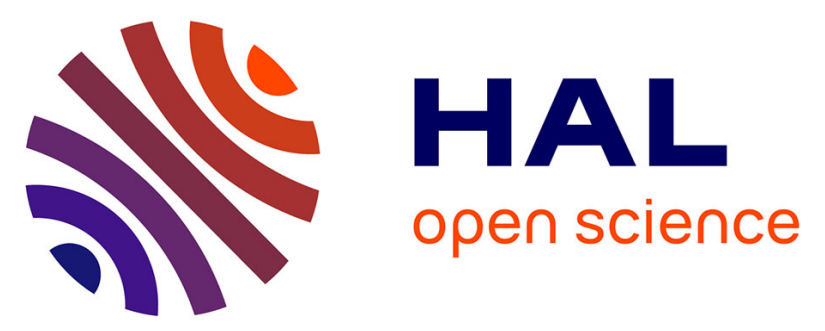

\title{
Non-linear electro-elastic coupling in highly strained zinc-blende compounds: InGaP/GaP [111] quantum wells
}

Laurent Pedesseau, Claudine Katan, Jean-Marc Jancu, Jacky Even

\section{- To cite this version:}

Laurent Pedesseau, Claudine Katan, Jean-Marc Jancu, Jacky Even. Non-linear electro-elastic coupling in highly strained zinc-blende compounds: InGaP/GaP [111] quantum wells. XV-th International Conference on High Pressure in Semiconductor Physics: HPSP-15, Jul 2012, Montpellier, France. pp.765-768, 10.1002/pssb.201200498 . hal-00805344

\section{HAL Id: hal-00805344 https://hal.science/hal-00805344}

Submitted on 28 Mar 2013

HAL is a multi-disciplinary open access archive for the deposit and dissemination of scientific research documents, whether they are published or not. The documents may come from teaching and research institutions in France or abroad, or from public or private research centers.
L'archive ouverte pluridisciplinaire HAL, est destinée au dépôt et à la diffusion de documents scientifiques de niveau recherche, publiés ou non, émanant des établissements d'enseignement et de recherche français ou étrangers, des laboratoires publics ou privés. 


\title{
Non-linear electro-elastic coupling in highly strained zinc-blende compounds: InGaP/GaP [111] quantum wells
}

\author{
Laurent Pedesseau ${ }^{*}, 1$, Claudine Katan ${ }^{1,2}$, Jean-Marc Jancu ${ }^{1}$, and Jacky Even ${ }^{1}$ \\ ${ }^{1}$ Université Européenne de Bretagne, INSA-FOTON, UMR 6082, 35708 Rennes, France \\ ${ }^{2}$ CNRS, Institut des Sciences Chimiques de Rennes, UMR 6226, 35042 Rennes, France
}

Received ZZZ, revised ZZZ, accepted ZZZ

Published online ZZZ (Dates will be provided by the publisher.)

Keywords: electrostriction, non-linear piezoelectricity, DFT

* Corresponding author: laurent.pedesseau@insa-rennes.fr

\begin{abstract}
A symmetry-based thermodynamical model of thirdorder electro-elastic coupling is applied to zinc-blende semiconductors. Density Functional Theory (DFT) is used to calculate the complete set of linear and non-linear coefficients. The entanglement of non-linear piezoelectricity, electrostriction and other non-linear phenomena, is studied in details at the same level of theory. Numeri-
\end{abstract}

1 Introduction

A complete model of third-order electro-elastic coupling has recently been proposed [1-2]. It is an extension of a previous thermodynamical approach [3] (quoted as ATK model in this paper) which is combined systematically with symmetry analyses and DFT calculations to evaluate consistently the various linear and non-linear coefficients, especially in non-centrosymmetric materials. Symmetry properties of third-order elastic constants [4] and thirdorder coupled constants [5] must be studied carefully. In this work, third-order coefficients are determined for zincblende bulk compounds from finite difference studies of material's polarization or stress tensor under various electrical or strain conditions. Our previous study [1-2] and ATK model [3] show that coefficients defined for a specific thermodynamical potential should not be mixed with others for the interpretation of experimental results [6]. Non-linear piezoelectric and electrostrictive components are indeed entangled [1]. Non-linear elastic and piezoelectric effects in semiconductors have attracted attention in the last few years because highly strained materials are used intentionally to grow lattice mismatched nanostructures like quantum wells or quantum dots [7-11]. We propose to extend our work on wurtzite nanostructures $[1,2]$ cal results for $\operatorname{In}_{x} \mathrm{Ga}_{(1-\mathrm{x})} \mathrm{P} / \mathrm{GaP}$ [111] quantum wells show the predominance of the non-linear piezoelectricity contribution. However, for a coupled non-linear model, the electrostriction has also to be taken into account. Finally, the non-linear elasticity gives a significant correction on the strain calculation. and our preliminary work on zinc-blende nanostructures [7] to InGaP/GaP [111] quantum wells.

\section{Determination of non-linear coefficients us-} ing density functional theory

The method of density-functional perturbation theory (DFPT) may be used to calculate various physical responses. In fact the efficient use of the " $2 n+1$ " theorem [12], using only by-products of a first-order perturbation calculation, in principle gives the second and third-order derivatives of the total energy, if the atomic-displacement variables are eliminated.

Second-order derivatives may be used with an existing DFPT implementation [13] to calculate various physical response properties of insulating crystals, including elastic constants, linear piezoelectric tensors, linear dielectric susceptibility, as well as tensor properties related to internal atomic displacements like Born charges. Non-linear electrical susceptibility, elasticity, piezoelectricity and electrostriction, are related to third-order derivatives of the total energy [1-3]. However, most practical implementations of the DFPT are restricted to some quantities related to inter- 
nal atomic displacements. Finite differences of polarization and stress tensor components were then calculated as a function of the electric field and strain tensor components $[1,2,7]$. DFT simulations are performed using a state of the art DFT implementation [13] within the local density approximation (LDA). Plane wave basis sets were used with a kinetic energy cutoff of $950 \mathrm{eV}$ after convergence studies. The sets of k-points are generated following the procedure of Pack and Monkhorst and Pack [14] namely 10x10x10. The computation of all the non-linear electro-elastic coefficients are presented in table 1 for the InP and GaP materials (Table 1 ).

Table 1 Electro-elastic non-linear constants of InP and GaP zincblende materials calculated using DFT-LDA simulations (ABINIT code). The lattice parameter, the linear and non-linear elastic constants, the electrostrictive constants, the linear and nonlinear dielectric constants and the linear and non-linear piezoelectric constants are listed from top to bottom.

\begin{tabular}{ccc}
\hline & InP & $\mathrm{GaP}$ \\
\hline $\mathrm{a}[\AA]$ & 5.85 & 5.46 \\
$\mathrm{c}_{11}[\mathrm{GPa}]$ & 98.2 & 135.9 \\
$\mathrm{c}_{12}[\mathrm{GPa}]$ & 54.6 & 61.9 \\
$\mathrm{c}_{44}[\mathrm{GPa}]$ & 44.6 & 67.1 \\
$\mathrm{c}_{111}[\mathrm{GPa}]$ & 56.3 & -284.9 \\
$\mathrm{c}_{112}[\mathrm{GPa}]$ & -387.4 & -492.1 \\
$\mathrm{c}_{123}[\mathrm{GPa}]$ & 131.9 & 264.2 \\
$\mathrm{c}_{144}[\mathrm{GPa}]$ & 61.4 & 48.0 \\
$\mathrm{c}_{155}[\mathrm{GPa}]$ & -12.6 & -47.0 \\
$\mathrm{c}_{456}[\mathrm{GPa}]$ & 42.0 & 46.8 \\
$\mathrm{~L}_{11}$ & 37.3 & 21.0 \\
$\mathrm{~L}_{12}$ & 18.7 & 5.4 \\
$\mathrm{~L}_{44}$ & 90.4 & 23.8 \\
$\varepsilon_{11}$ & 13.0 & 10.7 \\
$\varepsilon_{123}\left[10^{-12} \mathrm{~m} / \mathrm{V}\right]$ & -442.7 & -229.1 \\
$\mathrm{e}_{14}\left[\mathrm{C} / \mathrm{m}^{2}\right]$ & -0.0095 & -0.1098 \\
$\mathrm{~B}_{114}\left[\mathrm{C} / \mathrm{m}^{2}\right]$ & -1.06 & -0.83 \\
$\mathrm{~B}_{124}\left[\mathrm{C} / \mathrm{m}^{2}\right]$ & -3.82 & -3.43 \\
$\mathrm{~B}_{156}\left[\mathrm{C} / \mathrm{m}^{2}\right]$ & -0.45 & -0.92 \\
\hline
\end{tabular}

On figure 1 , the linear piezoelectric coefficient $\mathrm{e}_{14}$ is plotted as a function of the Indium fraction in $\operatorname{In}_{\mathrm{x}} \mathrm{Ga}_{(1-\mathrm{x})} \mathrm{P}$ alloy, assuming a Vegard's law. This coefficient is very small for pure InP. It is then expected that the electrostriction, and non-linear piezoelectric effects may play a significant role in InP highly strained nanostructures.

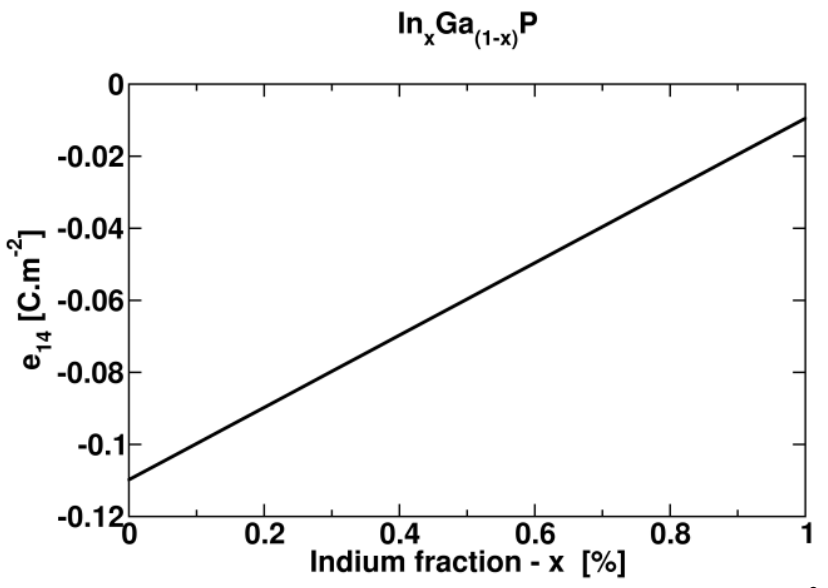

Figure 1 Linear piezoelectric coefficient $\mathrm{e}_{14}$ [in C.m $\left.{ }^{-2}\right]$ versus Indium fraction $\mathrm{x}$ [in percentage] for the model $\mathrm{In}_{\mathrm{x}} \mathrm{Ga}_{(1-\mathrm{x})} \mathrm{P}$ compounds.

3 Analytical study of electro-elastic in $\ln _{x} G a_{(1-}$ x) P/GaP [111] quantum wells

The case of the $\operatorname{In}_{\mathrm{x}} \mathrm{Ga}_{(1-\mathrm{x})} \mathrm{P}$ alloy biaxially strained on a $\mathrm{GaP}$ [111] misoriented substrate is considered.

The strain tensor is defined as:

$\left\{\begin{array}{c}\eta_{1}=\eta_{2}=\eta_{3}=\eta \\ \eta_{4}=\eta_{5}=\eta_{6}=2 \chi\end{array}\right.$

We can rewrite $\eta$ and $\chi$ as a function of $\eta_{\perp}$ and $\eta_{/ /}$ such as:

$$
\left\{\begin{array}{l}
\chi=\frac{\eta_{\perp}-\eta_{\|}}{3} \\
\eta=\frac{2 \eta_{\|}+\eta_{\perp}}{3}
\end{array}\right.
$$

The stress tensor and the electric field is given by :

$$
\left\{\begin{array}{l}
\sigma=\sigma_{1}=\sigma_{2}=\sigma_{3} \\
\varphi=\sigma_{4}=\sigma_{5}=\sigma_{6} \\
\mathrm{E}=\mathrm{E}_{1}=\mathrm{E}_{2}=\mathrm{E}_{3}
\end{array}\right.
$$

Taking into account non-linear electro-elastic coupling, the strain tensor components and the polarization are equal to: 


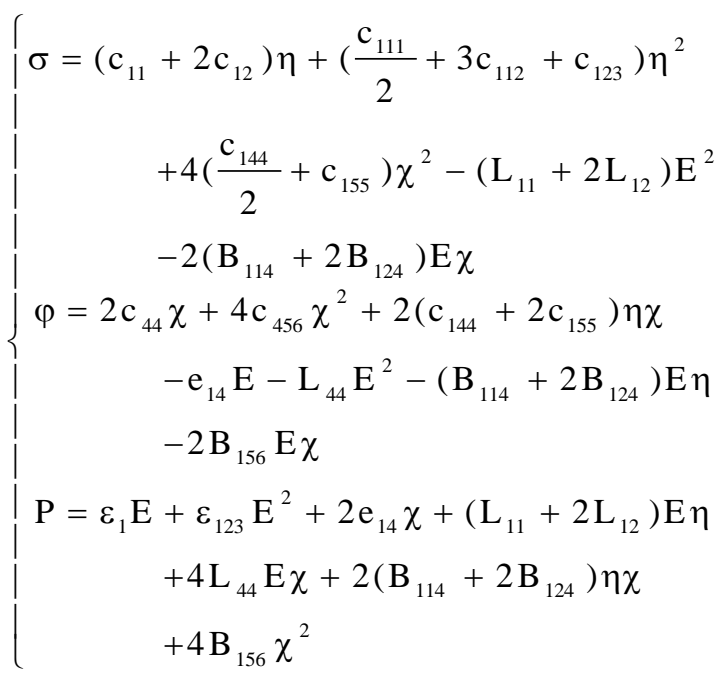

In order to use a stress-free surface condition for the [111] orientation, a transformation matrix $\hat{U}$ is used to obtain the tensor components in a suitable reference frame [15]:

$$
\hat{U}=\left|\begin{array}{ccc}
\frac{1}{\sqrt{6}} & -\frac{1}{\sqrt{2}} & \frac{1}{\sqrt{3}} \\
\frac{1}{\sqrt{6}} & \frac{1}{\sqrt{2}} & \frac{1}{\sqrt{3}} \\
-\frac{\sqrt{2}}{3} & 0 & \frac{1}{\sqrt{3}}
\end{array}\right|
$$

In this new reference frame (a prime is used), the stress tensor components are given by:

$$
\left\{\begin{array}{l}
\sigma_{1}^{\prime}=\sigma_{2}^{\prime}=\sigma-\varphi \\
\sigma_{3}^{\prime}=\sigma+2 \varphi=0 \\
\sigma_{4}^{\prime}=\sigma_{5}^{\prime}=\sigma_{6}^{\prime}=0
\end{array} \quad\right. \text { (free surface condition ) }
$$

The polarization is calculated from:

$$
\mathrm{P}_{3}^{\prime}=\sqrt{3} \mathrm{P}
$$

When non-linear phenomena are neglected, simple well-known analytical expressions [16] are recovered from this model for the strain tensor components:

$$
\left\{\begin{array}{l}
\eta_{1}^{\prime}=\eta_{2}^{\prime}=\eta_{/ /} \\
\eta_{3}^{\prime}=-\frac{2 c_{11}+4 c_{12}-4 c_{44}}{c_{11}+2 c_{12}+4 c_{44}} \eta_{/ /} \\
\eta_{4}^{\prime}=\eta_{5}^{\prime}=\eta_{6}^{\prime}=0
\end{array}\right.
$$

\section{Numerical results for $\ln _{x} G_{a}(1-x) P / G a P$ [111] quantum wells}

On figure 2, the out of plane [111] strain of $\operatorname{In}_{\mathrm{x}} \mathrm{Ga}_{(1-\mathrm{x})} \mathrm{P}$ is presented as a function of the Indium fraction. The nonlinear corrections increase with the Indium fraction and reach a maximum of about $15 \%$ for pure InP. The main correction is attributed to non-linear elasticity.

$$
\ln _{x} G a_{(1-x)} P / G a P[111]
$$

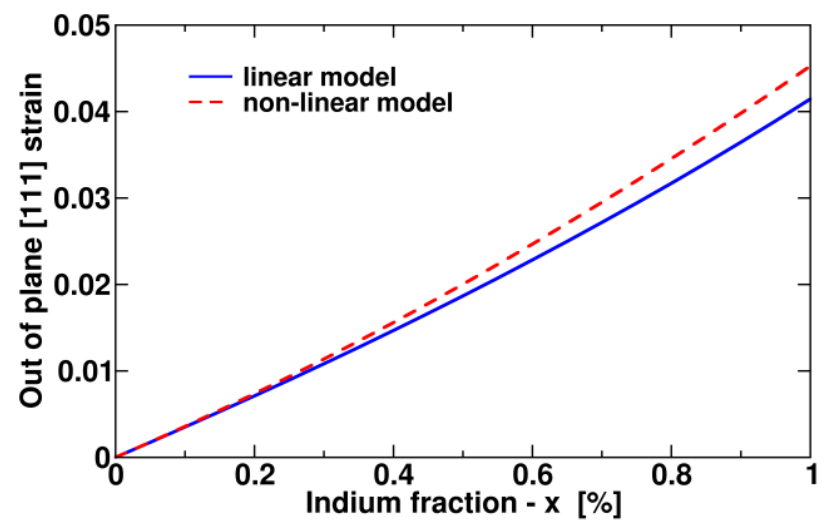

Figure 2 Out of plane [111] strain of $\operatorname{In}_{x} G_{(1-x)} P$ versus Indium fraction $\mathrm{x}$ in percentage for the linear and non-linear model in the case of $\operatorname{In}_{x} \mathrm{Ga}_{(1-x)} \mathrm{P} / \mathrm{GaP}[111]$ heterostructure.

On figure 3, the electric field along the 111 direction is plotted as a function of the Indium fraction. A linear model, the effects of non-linear elasticity, electrostriction and nonlinear piezoelectricity, and finally a complete non-linear model are presented. The internal electric field undergoes a sign change for intermediate In content, as a result of the competition between linear and non-linear effects. This field reaches a large negative value for pure InP and is mainly associated to non-linear piezoelectricity but also to electrostriction. 


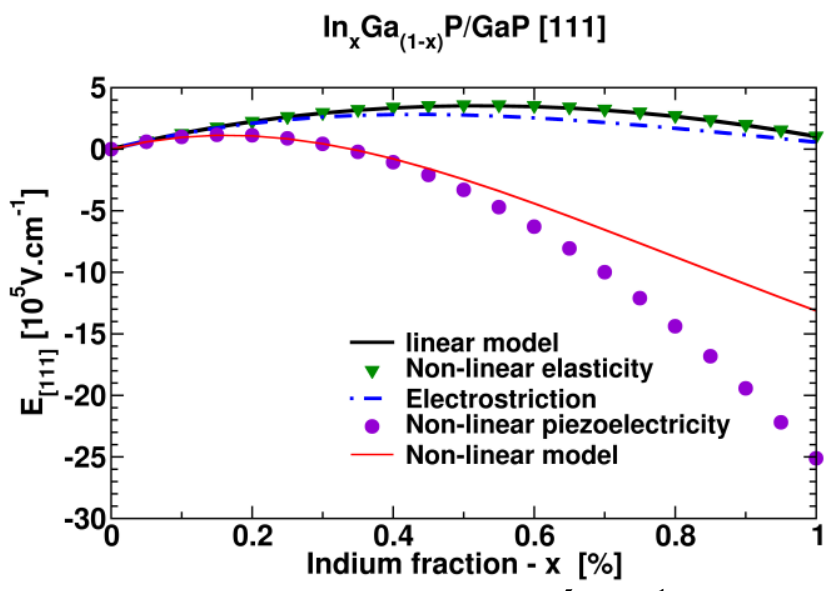

Figure 3 Electric field $\mathrm{E}_{[111]}$ [in $10^{5} \mathrm{~V} . \mathrm{cm}^{-1}$ ] in $\mathrm{In}_{\mathrm{x}} \mathrm{Ga}_{(1-}$ ${ }_{x)} \mathrm{P}$ biaxially strained on $\mathrm{GaP}$ [111] versus Indium fraction $\mathrm{X}$ [in percentage] for the linear model, non-linear elasticity, electrostriction, non-linear piezoelectricity, and non-linear model.

On figure 4, we focused on the positive value of the internal electric field. A maximum is reached at $\mathrm{x}=0.52$ and $\mathrm{x}=0.14$ for the linear model and for the non-linear model respectively. This large difference is also mainly associated to the non-linear piezoelectricity. When only electrostriction is added to the linear model, the maximum is shifted to $\mathrm{x}=0.42$.

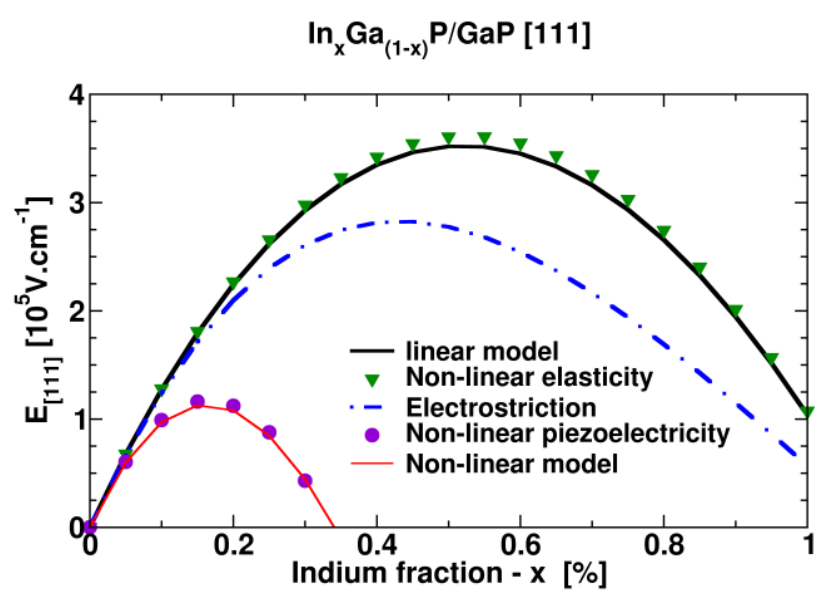

Figure 4 Zoom on the Electric field $\mathrm{E}_{[111]}\left[\right.$ in $\left.10^{5} \mathrm{~V} . \mathrm{cm}^{-1}\right]$ maximum versus Indium fraction $\mathrm{x}$ [in percentage] for the linear model, non-linear elasticity, electrostriction, non-linear piezoelectricity, and non-linear model with $\operatorname{In}_{\mathrm{x}} \mathrm{Ga}_{(1-\mathrm{x})} \mathrm{P} / \mathrm{GaP}$ [111].

\section{Conclusion}

A complete set of non-linear electro-elastic constants has been calculated for InP and GaP zinc-blende bulk materials using Density Functional Theory. A symmetry based analytical model is proposed for the non-linear stress and polarization in biaxially strained heterostructures on
[111] substrates. Numerical results for $\operatorname{In}_{x} \mathrm{Ga}_{(1-\mathrm{x})} \mathrm{P} / \mathrm{GaP}$ [111] quantum wells indicate that non-linear piezoelectricity is the most important contribution to polarization, but electrostriction has to be taken into account in a coupled non-linear model. Non linear elasticity yields a significant correction for strain calculation.

\section{Acknowledgements}

This work was performed using HPC resources from GENCI-CINES-IDRIS grant 2012-c2012096724.

\section{References}

[1] L. Pedesseau, C. Katan, and J. Even, Appl. Phys. Lett. 100, 031903 (2012).

[2] J. Even, L. Pedesseau, C. Hajlaoui, C. Katan, and J.-M Jancu, J. Phys.: Conf. Ser. 367, 012005 (2012).

[3] W. Adam, J. Tichy, and E. Kittinger, J. Appl. Phys. 64, 2556 (1988).

[4] K. Brugger, J. Appl. Phys. 36, 759 (1965).

[5] H. Grimmer, Acta Cryst A63, 441 (2007).

[6] R. E. Newnham, V. Sundar, R. Yimnirun, J. Su, and Q. M. Zhang, J. Phys. Chem. B101, 10141 (1997).

[7] G. Bester, X. Wu, D. Vanderbilt, and A. Zunger, Phys. Rev. Lett. 96, 187602 (2006).

[8] G. Bester, A. Zunger, X. Wu, and D. Vanderbilt, Phys. Rev. B74, 081305 (2006).

[9] J. Even, F. Dore, C. Cornet, L. Pedesseau, A. Schliwa, and D. Bimberg, Appl. Phys. Lett. 91, 122112 (2007).

[10] L. Pedesseau, J. Even, F. Dore, and C. Cornet, AIP Conf. Proc. 963, 1331 (2007).

[11] A. Beya-Wakata, P.-Y. Prodhomme, and G. Bester, Phys. Rev. B84, 195207 (2011)

[12] D. R. Hamann, X. Wu, K. M. Rabe, and D. Vanderbilt, Phys. Rev. B71, 035117 (2005).

[13] X. Gonze, B. Amadon, P. M. Anglade, J. M. Beuken, F. Bottin, P. Boulanger, F. Bruneval, D. Caliste, R. Caracas, M Cote, T. Deutsch, L. Genovese, Ph. Ghosez, M. Giantomassi, S. Goedecker, D. R. Hamann, P. Hermet, F. Jollet, G. Jomard, S. Leroux, M. Mancini, S. Mazevet, M. J. T. Oliveira, G. Onida, Y. Pouillon, T. Rangel, G. M. Rignanese, D. Sangalli, R. Shaltaf, M. Torrent, M. J. Verstraete, G. Zerah, J. W. Zwanziger, Computer Phys. Commun. 180, 2582 (2009).

[14] H. J. Monkhorst, and J. D. Pack, Phys. Rev. B13, 5188 (1976).

[15] E. Pan, J. Appl. Phys. 91, 6379 (2002).

[16] K. Yang, T. Anan, and L. J. Schowalter, Appl. Phys. Lett. 65, 2789 (1994) 